\title{
Para-aortic Area Dissection and Left Pelvic Space Dissection in a Case of Carcinoma Ovary
}

Agniv Sarkar ${ }^{1}$, Manoranjan Mahapatra ${ }^{2}$, Jita Parija $^{3}$, Richi Khandelwal ${ }^{4}$, Smrutisudha Pattnaik $^{5}$

\author{
Abstract \\ pararectal space displaying hypogastric plexus. \\ Keywords: CA 125, CA ovary, Ovarian carcinoma, Ovary. \\ Journal of South Asian Federation of Obstetrics and Gynaecology (2021): 10.5005/jp-journals-10006-1925
}

A 52-year-old patient of carcinoma (CA) ovary was put for primary cytoreductive surgery. The two pictures depict para-aortic space and left

A 56-year-old patient, P2L2, was admitted with abdominal distension for the last 2 months. Clinically she had moderate ascites and right-sided adnexal $8 \times 7 \mathrm{~cm}$ cystic mass. Her CA 125 level was $1182 \mathrm{IU} / \mathrm{L}$ and carcinoembryonic antigen (CEA) was $1.2 \mathrm{IU} / \mathrm{L}$. Contrast enhanced CT scan (CECT) revealed the mass with $8.2 \times 6.7 \mathrm{~cm}$ size with moderate ascites. No lymphadenopathy was there. Patient was put for primary cytoreduction surgery (CRS). This image shows the para-aortic area dissection during lymphadenectomy.

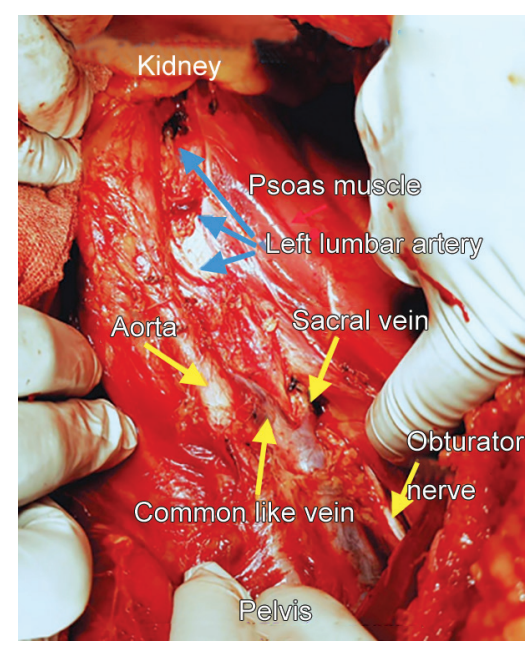

${ }^{1-5}$ Department of Gynecological Oncology, Acharya Harihar Post Graduate Institute of Cancer, Cuttack, Odisha, India

Corresponding Author: Agniv Sarkar, Department of Gynecological Oncology, Acharya Harihar Post Graduate Institute of Cancer, Cuttack, Odisha, India, Phone: +91 7980060869, e-mail: sarkaragniv@yahoo.in

How to cite this article: Sarkar A, Mahapatra M, Parija J, et al. Para-aortic Area Dissection and Left Pelvic Space Dissection in a Case of Carcinoma Ovary. J South Asian Feder Obst Gynae 2021;13(4):278.

Source of support: Nil

Conflict of interest: None

Also, the left pelvic space showing hypogastric plexus is beautifully shown in another image. Patient consent was taken beforehand.

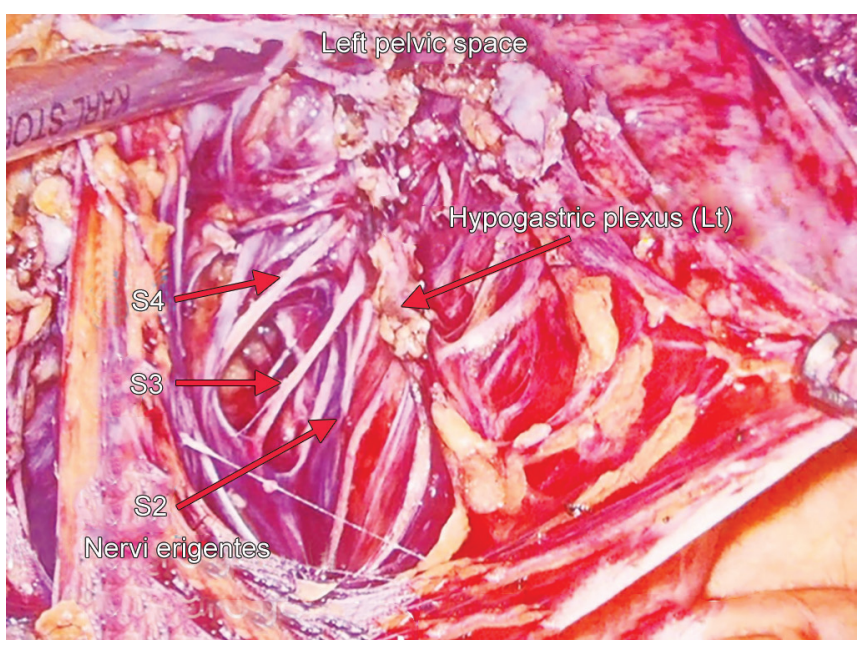

(-) The Author(s). 2021 Open Access This article is distributed under the terms of the Creative Commons Attribution 4.0 International License (https://creativecommons. org/licenses/by-nc/4.0/), which permits unrestricted use, distribution, and non-commercial reproduction in any medium, provided you give appropriate credit to the original author(s) and the source, provide a link to the Creative Commons license, and indicate if changes were made. The Creative Commons Public Domain Dedication waiver (http://creativecommons.org/publicdomain/zero/1.0/) applies to the data made available in this article, unless otherwise stated. 